\title{
Sociodemographic and Clinical Profile of Patients Attending a Private Psychiatry Clinic in Assam, India
}

\author{
Prosenjit Ghosh ${ }^{1}$, Monu Doley ${ }^{2}$, Anshuman Gogoi ${ }^{3}$
}

\begin{abstract}
Background: Mental illness is a public health issue all over the world. The morbidity pattern in private clinics differs significantly from general hospitals. Private psychiatric clinics provide help for large number of our population, but they have seldom been evaluated systematically. It has been observed that many patients particularly from upper socioeconomic background prefer visiting a private clinic. Hence, the study is planned in this direction. The study was aimed to assess the morbidity pattern of psychiatric patients attending a private psychiatric clinic. Aim: To analyze the clinical and sociodemographic characteristics of the clients attending the private clinic and to study the pattern of follow-up. Materials and methods: All records from February 1, 2019 to April 30, 2019 were analyzed. This is a descriptive study. Results and conclusion: A total of 1,020 new patients visited the clinic in this period. We found that mental disorders comprise a wide variety of disorders-mainly psychotic, mood disorders, and neurotic disorders. They affect the most productive age groups, almost equally affect both the genders, and there was a slight preponderance of rural patients.

Keywords: Analysis of a psychiatric clinic, Demographic profile, Dropout, Morbidity, Private psychiatric clinic. Indian Journal of Private Psychiatry (2019): 10.5005/jp-journals-10067-0045
\end{abstract}

\section{BACKGROUND}

In developing countries with acute shortages of mental health professionals, the delivery of mental health services through general healthcare is considered as the most viable strategy for increasing the access of underserved populations to mental healthcare. Mental health facilities in the government setup are very limited, and a vast population of this country's mental healthcare is provided by private practitioners and hospitals. According to the World Mental Health Atlas $^{1}$ 2014, there were 0.3 psychiatrist per lakh of population in India. Psychologists and psychiatric social workers were even fewer.

Mental illnesses are the major source of morbidity across both developed and developing countries. Mental illnesses affect people of all age groups. They are an important health problem that refers to disorders of mood, thought, cognition, intelligence, personality, substance abuse, and adjustment with the people around them. The spectrum of this issue ranges from simple anxiety disorder to depressive disorders to treatment-resistant schizophrenia and even death. ${ }^{2}$ The global neglect of mental health is well-documented. Mental health issues are neglected in policy, planning, and funding. In all countries, there is a significant gap between the prevalence of mental disorders, on one hand, and the number of people receiving care and treatment, on the other hand. ${ }^{3}$ In low and middle income countries (LAMIC) countries, the gap is more: $67 \%$ treatment gap for major depression in Africa, compared with a $45 \%$ gap in Europe. ${ }^{4}$ It has been estimated that globally more than 400 million people have been affected by some kind of mental illness during their lifetime and majority of them residing in developing countries. ${ }^{5}$ According to the WHO report of 2014, nearly 83 million people of the United States have been diagnosed with psychiatric disorder; among all the psychiatric illnesses, depression is the most common. The WHO European Region report stated that 1 out of 15 people suffer from major depression, which is remarkably high and quite alarming. ${ }^{6}$ The study of South Africa ${ }^{7}$ reported the lifetime prevalence of common mental disorders to be about $30 \%$. The Ministry of Health and Family welfare of India ${ }^{8}$

\footnotetext{
${ }^{1-3}$ Department of Psychiatry, Silchar Medical College and Hospital, Silchar, Assam, India

Corresponding Author: Prosenjit Ghosh, Department of Psychiatry, Silchar Medical College and Hospital, Silchar, Assam, India, Phone: +91 9435072563, e-mail: p_ghosh72@yahoo.com

How to cite this article: Ghosh P, Doley M, Gogoi A. The Sociodemographic and Clinical Profile of Patients Attending a Private Psychiatry Clinic in Assam, India. Ind J Priv Psychiatry 2019;13(2):52-57. Source of support: Nil

Conflict of interest: None
}

suggested the lifetime prevalence of mental disorders to be nearly $12 \%$, which is likely to increase to almost $15 \%$ by the year 2020 .

The present work was undertaken with the aim to study the sociodemographic characteristics and the clinical profile of patients attending the private psychiatry clinic situated in a district headquarter of southern Assam, India.

\section{Aims and OBjectives}

To analyze the sociodemographic and diagnostic distribution of the patients attending the clinic and to study the pattern of follow-up.

\section{Materials and Methods}

The first author is running a private psychiatric clinic, and the relevant data of the patients coming to the clinic during the study period were recorded digitally. This is a retrospective study where case records of all new patients attending the private psychiatry clinic and diagnosed according to ICD- $10^{9}$ were analyzed.

\section{Analysis of the Data}

These data are for the period from February 1, 2019 to April 30, 2019. The recordkeeping was started from January 2019 and a 3-month

() The Author(s). 2019 Open Access This article is distributed under the terms of the Creative Commons Attribution 4.0 International License (https://creativecommons. org/licenses/by-nc/4.0/), which permits unrestricted use, distribution, and non-commercial reproduction in any medium, provided you give appropriate credit to the original author(s) and the source, provide a link to the Creative Commons license, and indicate if changes were made. The Creative Commons Public Domain Dedication waiver (http://creativecommons.org/publicdomain/zero/1.0/) applies to the data made available in this article, unless otherwise stated. 
Table 1: Sociodemographic details—age, gender, residence, and marital status distribution

\begin{tabular}{|c|c|c|}
\hline & Frequency & Percentage \\
\hline \multicolumn{3}{|c|}{ Age distribution (years) } \\
\hline $0-10$ & 16 & 1.6 \\
\hline $11-20$ & 101 & 9.9 \\
\hline $21-30$ & 244 & 23.9 \\
\hline $31-40$ & 235 & 23.0 \\
\hline $41-50$ & 204 & 20.0 \\
\hline $51-60$ & 105 & 10.3 \\
\hline $61-70$ & 70 & 6.9 \\
\hline $71-80$ & 35 & 3.4 \\
\hline $81-90$ & 8 & 0.8 \\
\hline$>90$ & 2 & 0.2 \\
\hline Total & 1,020 & 100.0 \\
\hline \multicolumn{3}{|c|}{ Gender distribution } \\
\hline Male & 535 & 52.5 \\
\hline Female & 485 & 47.5 \\
\hline Total & 1,020 & 100.0 \\
\hline \multicolumn{3}{|l|}{ Residence } \\
\hline Rural & 566 & 55.5 \\
\hline Urban & 454 & 44.5 \\
\hline Total & 1,020 & 100.0 \\
\hline \multicolumn{3}{|c|}{ Marital status } \\
\hline Married & 610 & 59.8 \\
\hline Single & 345 & 33.8 \\
\hline Widowed & 46 & 4.5 \\
\hline Divorced & 19 & 1.9 \\
\hline Total & 1,020 & 100.0 \\
\hline
\end{tabular}

study period was chosen as average attendance per month in the clinic was 300 for last few years. All records were analyzed by the second author. Diagnosis was reassessed after analyzing the record again and many diagnoses were changed. The ICD-10 diagnostic system was used. But, sometimes, symptomatic diagnosis like headache has also been used. Improvement has been recorded as mentioned in the case record on the last entry. The record may have indicated improved, unchanged, or worse. No scales were used, and these could be taken as subjective assessment of the patients, their caretakers, and the clinicians. Data were analyzed using SPSS version 21 and association was seen with the Chi-square test and the significance level was set at 0.05 .

\section{Results}

After the study period was over, total 1,020 patient's data were analyzed. A total of 1,020 patients who attended a private psychiatric clinic in a town in Assam during the study period were included in the study. Of the 1,020 patients, 535 (52.5\%) were males and 485 (47.5\%) were females. Nearly $67 \%$ of the study population belonged to the $21-50$ years' age group that is economically most productive. A total of 610 patients (59.8\%) were married, 345 (33.8\%) were unmarried, 46 (4.5\%) were widowed, and 19 (1.9\%) were separated (Table 1).

As the study was conducted in a town, 566 patients $(55.5 \%)$ were from urban area and remaining 454 (45.5\%) from rural area.
Table 2: Sociodemographic variables-educational status and socioeconomic status

\begin{tabular}{lcc}
\hline & Frequency & Percentage \\
\hline Educational status & 62 & 6.1 \\
Illiterate & 111 & 10.9 \\
Primary school (Std. 1-5) & 154 & 15.1 \\
Middle school (Std. 6-8) & 354 & 34.7 \\
Secondary school (Std. 9-10) & 158 & 15.5 \\
Higher secondary & 137 & 13.4 \\
Graduate & 27 & 2.6 \\
Postgraduate (MA, MSc, MBA, MCA) & 17 & 1.7 \\
Diploma, B.Tech, LLB, MBBS, PhD & 1,020 & 100.0 \\
Total & & \\
Socioeconomic status & 168 & 16.5 \\
Lower & 657 & 64.4 \\
Lower middle & 179 & 17.5 \\
Middle & 16 & 1.6 \\
Upper & 1,020 & 100.0 \\
Total & & \\
\hline
\end{tabular}

Table 3: Diagnostic profile of patients

\begin{tabular}{lcc}
\hline Diagnosis & Frequency & Percentage \\
\hline F00-F09 & 27 & 2.6 \\
F10-F19 & 21 & 2.1 \\
F20-F29 & 371 & 36.4 \\
F30-F39 & 217 & 21.3 \\
F40-F48 & 224 & 22.0 \\
F50-F59 & 14 & 1.4 \\
F60-F69 & 1 & 0.1 \\
F70-F79 & 22 & 2.2 \\
F80-F89 & 4 & 0.4 \\
F90-F98 & 7 & 0.7 \\
Others & 112 & 11.0 \\
Total & 1,020 & 100.0 \\
\hline
\end{tabular}

Nearly $94 \%$ of the patients were literate, $35 \%$ had completed high school and $13.4 \%$ completed graduation, and $4.3 \%$ had either postgraduation or professional education as shown in Table 2. A majority of the study population was economically well-off with $81.9 \%$ belonging to the middle and lower-middle social class. Out of the 1,020 patients, $36.4 \%$ were suffering from schizophrenia and other psychotic disorders, $22 \%$ were suffering from neurotic, stressrelated, and somatoform disorders, $21.3 \%$ from mood disorders, $11 \%$ others (including migraine, seizure, vertigo, and NPH), $2.6 \%$ from organic mental disorders, $2.2 \%$ from mental retardation, $2.1 \%$ from substance dependence disorders, $1.4 \%$ from behavioral problems associated with physiological disturbances, $0.7 \%$ from behavioral disorders occurring in childhood and adolescence, and $0.4 \%$ from disorders of psychological development (Table 3).

Majority of our patients (94\%) were either referred by family/ friends or self-referred. Analysis of the data revealed that almost $40 \%$ dropout rate after first visit. The association between diagnostic groups and place of residence was statistically significant $(p=0.002)$. The association between diagnostic groups and gender was highly significant $(p=0.000)$. The analysis of association 
between diagnosis and the socioeconomic status was also significant $(p=0.03)$.

\section{Discussion}

Mental disorders are an important cause of long-term morbidity, disability, and poor quality of life. Various epidemiological surveys in Asia have indicated that there are 680 million people who are likely to succumb to psychiatric disorder. In terms of services, there is less than 1 mental health professional per 100,000 populations whereas the desirable number is 3-4 psychiatrists per 100,000 populations. People with mental illnesses, in the Indian subcontinent, often seek help from traditional healers. This study was carried out to depict and point out the observed trends through a sociocultural perspective to determine the demographic and clinical characteristics of clients seeking consultation from a private psychiatric clinic in the urban region of northeastern India, during the 3-month period of 2019 (Tables 4 and 5).

Increased prevalence of morbidity $(58.4 \%)$ is seen in the younger age group in our sample. This trend was earlier demonstrated by many researchers from Asia-Kameshvell et al. (India), Khattri et al. (Nepal), Jaju et al. (Oman), and Soren et al. (India). ${ }^{10-13}$ But, there is no consensus as to which age group is the most vulnerable to mental illness. The rates of psychiatric disorders fluctuate according to geographic, ethnic, and socioeconomic status. ${ }^{14,15}$ However, it is widely agreed that psychiatric disorders often affect young people who are in the midst of their most productive years of life. ${ }^{12}$

Earlier studies have reported a strong association between gender and mental illness, with the female gender being the most prominent of the risk factors in certain psychiatric disorders. ${ }^{16,17}$ In our study sample of 1,020 patients, a small preponderance of males $(52.5 \%)$ over females was noted, which is consistent with the findings of Regmi et al., ${ }^{18}$ Shrestha ${ }^{19}$ and Kameshvell et al. ${ }^{11}$ This male preponderance may reflect the gender bias in a patrilineal family system in psychiatric help-seeking behavior. The gender segregation and other sociocultural factors inherent in such paternalistic society may prevent women from going outside to seek help for mental illness. ${ }^{20}$

In many Asian communities, mental illnesses are often dealt by traditional healing systems. Due to the fact that primary healthcare seldom caters to the needs of people with mental illnesses, the first point of contact for them is tertiary care, and the majority of our clients seeking consultation presented themselves at the clinic or were referred by family. This is consistent with the low observed referrals from other medical specialties. It is possible that patients may think that a referral to a mental health specialist means that they are "crazy." For these reasons, the majority of referrals (94\%) were classified as "self and family referrals."

As the study place was in a town, majority of the patients (55.5\%) were from urban background and from rural area (45.5\%). This may be due to easy accessibility, better awareness, and greater

Table 4: Diagnosis vs residence cross-tabulation $(p=0.002)$

\begin{tabular}{|c|c|c|c|c|c|}
\hline & & & \multicolumn{2}{|c|}{ Residence } & \multirow[b]{2}{*}{ Total } \\
\hline & & & Rural & Urban & \\
\hline \multirow[t]{22}{*}{ Diagnosis } & F00-F09 & Count & 16 & 11 & 27 \\
\hline & & $\%$ of total & 1.6 & 1.1 & 2.6 \\
\hline & F10-F19 & Count & 4 & 17 & 21 \\
\hline & & $\%$ of total & 0.4 & 1.7 & 2.1 \\
\hline & F20-F29 & Count & 225 & 146 & 371 \\
\hline & & $\%$ of total & 22.1 & 14.3 & 36.4 \\
\hline & F30-F39 & Count & 114 & 103 & 217 \\
\hline & & $\%$ of total & 11.2 & 10.1 & 21.3 \\
\hline & F40-F48 & Count & 116 & 108 & 224 \\
\hline & & $\%$ of total & 11.4 & 10.6 & 22.0 \\
\hline & F50-F59 & Count & 7 & 7 & 14 \\
\hline & & $\%$ of total & 0.7 & 0.7 & 1.4 \\
\hline & F60-F69 & Count & 0 & 1 & 1 \\
\hline & & $\%$ of total & 0.0 & 0.1 & 0.1 \\
\hline & F70-F79 & Count & 11 & 11 & 22 \\
\hline & & $\%$ of total & 1.1 & 1.1 & 2.2 \\
\hline & F80-F89 & Count & 1 & 3 & 4 \\
\hline & & $\%$ of total & 0.1 & 0.3 & 0.4 \\
\hline & F90-F99 & Count & 1 & 6 & 7 \\
\hline & & $\%$ of total & 0.1 & 0.6 & 0.7 \\
\hline & $\begin{array}{l}\text { Seizure, migraine, other headaches, } \\
\mathrm{NPH} \text {, neuropathy, } \mathrm{MCl} \text {, } \\
\text { parkinsonism, vertigo, CVA }\end{array}$ & Count & 71 & 41 & 112 \\
\hline & & $\%$ of total & 7.0 & 4.0 & 11.0 \\
\hline \multirow[t]{2}{*}{ Total } & & Count & 566 & 454 & 1,020 \\
\hline & & $\%$ of total & 55.5 & 44.5 & 100.0 \\
\hline
\end{tabular}


Table 5: Diagnosis vs gender cross-tabulation $(p=0.000)$

\begin{tabular}{|c|c|c|c|c|c|}
\hline & & & \multicolumn{2}{|c|}{ Gender } & \multirow[b]{2}{*}{ Total } \\
\hline & & & Male & Female & \\
\hline \multirow[t]{22}{*}{ Diagnosis } & F00-F09 & Count & 17 & 10 & 27 \\
\hline & & $\%$ of total & 1.7 & 1.0 & 2.6 \\
\hline & F10-F19 & Count & 21 & 0 & 21 \\
\hline & & $\%$ of total & 2.1 & 0.0 & 2.1 \\
\hline & F20-F29 & Count & 168 & 203 & 371 \\
\hline & & $\%$ of total & 16.5 & 19.9 & 36.4 \\
\hline & F30-F39 & Count & 120 & 97 & 217 \\
\hline & & $\%$ of total & 11.8 & 9.5 & 21.3 \\
\hline & F40-F48 & Count & 118 & 106 & 224 \\
\hline & & $\%$ of total & 11.6 & 10.4 & 22.0 \\
\hline & F50-F59 & Count & 10 & 4 & 14 \\
\hline & & $\%$ of total & 1.0 & 0.4 & 1.4 \\
\hline & F60-F69 & Count & 0 & 1 & 1 \\
\hline & & $\%$ of total & 0.0 & 0.1 & 0.1 \\
\hline & F70-F79 & Count & 14 & 8 & 22 \\
\hline & & $\%$ of total & 1.4 & 0.8 & 2.2 \\
\hline & F80-F89 & Count & 4 & 0 & 4 \\
\hline & & $\%$ of total & 0.4 & 0.0 & 0.4 \\
\hline & F90-F98 & Count & 6 & 1 & 7 \\
\hline & & $\%$ of total & 0.6 & 0.1 & 0.7 \\
\hline & $\begin{array}{l}\text { Seizure, migraine, other headaches, } \\
\mathrm{NPH} \text {, neuropathy, } \mathrm{MCl} \text {, } \\
\text { parkinsonism, vertigo, CVA }\end{array}$ & Count & 57 & 55 & 112 \\
\hline & & $\%$ of total & 5.6 & 5.4 & 11.0 \\
\hline \multirow[t]{2}{*}{ Total } & & Count & 535 & 485 & 1,020 \\
\hline & & $\%$ of total & 52.5 & 47.5 & 100.0 \\
\hline
\end{tabular}

vulnerability among urban people. It was observed that $28.3 \%$ of the study population were house wives, $16.9 \%$ were unemployed, and $14.2 \%$ were students. Unemployment that could be attributed to psychiatric disorders was lower when compared to the study by Fahmida et al. ${ }^{21}$ Family history of mental illness was present in $44.34 \%$ of patients, which was higher than with the findings of Shakya et al. ${ }^{22}$

In our study sample, approximately $94 \%$ subjects were literate and $4.3 \%$ had either postgraduation or professional education, and a majority of the study population was economically well-off with $81.9 \%$ belonging to middle and lower-middle social class. This may be due to increased awareness among the educated persons, affordability to pay the fee in a private clinic, and accessibility.

Our study also showed that the most commonly diagnosed mental disorders were schizophrenia and other psychotic disorders (36.4\%), followed by neurotic, stress-related, and somatoform disorders (22\%); mood disorders (21.3\%); others including migraine, seizure, vertigo, and NPH (11\%); organic mental disorders (2.6\%); mental retardation (2.2\%); substance dependence disorders (2.1\%); and behavioral problems associated with physiological disturbances (1.4\%), which was consistent with the findings of Shrestha ${ }^{19}$ and Soren et al. ${ }^{13}$ Whereas in other studies by Kameshvell, ${ }^{11}$ Regmi et al., ${ }^{18}$ and Shakya et al., neurotic or mood disorders were the main diagnostic groups. ${ }^{23}$

Soren et al..$^{13}$ in a study conducted in Jharkhand, India, found affective psychosis (31.9\%) as the main psychiatric problem followed by nonaffective psychosis (18.8\%), epilepsy (15.8\%), and neurotic disorder (11.2\%). In the study by Shrestha ${ }^{19}$ (1987), $63.7 \%$ of the patients were suffering from psychosis, $18 \%$ from neurosis, and $6 \%$ from epilepsy. Studies conducted in the outpatients in other parts of the world are rather similar to the findings of our study, in which most of the patients were suffering from psychotic disorders, and less were suffering from neurotic disorders-Choo ${ }^{24}$ and Uys et al. ${ }^{25}$ Our findings are in contrast to the findings of the study by Dubey, ${ }^{26}$ which was conducted in the rural community of Uttar Pradesh (India), in which about $44 \%$ of the patients were suffering from neurotic and related disorders and $9.1 \%$ from schizophrenia.

One of the important finding of our study was high number of patients with seizure disorder, headache, and vertigo (11.2\%). Similar findings were also reported by earlier researchers-Wig et al., ${ }^{27}$ Wright, ${ }^{28}$ and Sharma. ${ }^{29}$ Wright et al. had found that $32 \%$ of the patients were suffering from epilepsy. Epilepsy was seen in $9.4 \%$ of the population in the sample studied by Khattri et al. ${ }^{10}$ in Nepal. This may be due to lack of a neurologist or neurosurgeon in our study area.

This difference in the morbidity pattern may be due to cultural factors and setup of the study center, i.e., whether it is conducted in mental hospitals, psychiatric OPD of a general hospital, or private clinics. Psychosis predominates in mental hospitals, whereas a wider range including psychosis, mood disorders, neurosis, substance dependence, and organic mental disorder occurs in general hospital psychiatric units and private clinics. 
One of the most significant findings of our study is the high dropout rate after one visit. Nearly $40 \%$ discontinued treatment after first visit. Agarwal ${ }^{30}$ found nearly $50 \%$ dropout rate after the first visit. Could the dropout rate be a reflection of cultural acceptance of mental disorders in this country? People go to a doctor only when the disease produces discomfort/disability and the treatment is given up as soon as there is relief from the discomfort. Economic factors, distance from the clinic, poor rapport, lack of psychoeducation given to the caregivers, etc., have often been considered as key factors responsible for treatment discontinuation. They may play a role but there appear to be other factors that are responsible for treatment stoppage.

In the present study, gender difference in the morbidity pattern was found to be significant, which was similar to the studies of Reddy and Chandrashekar, ${ }^{31}$ Venkatesh et al., ${ }^{32}$ Mclean et al., ${ }^{33}$ and Rahman et al. ${ }^{34}$ and Kameshvell et al. ${ }^{11}$

Our study also found significant association between diagnostic subgroups and socioeconomic status, which was also reported by Kameshvell et al. ${ }^{11}$

\section{Strength of Our Study}

Large number of study subjects, assessment of dropout rate, private clinic setup in a multispecialty clinic where the chance of stigma was less.

\section{Limitations of the Study}

We did not use any scale for the assessment of severity of illness and level of impairment, we did not assess the cause of dropout, and there was evaluation of the personality profile of the study subjects. Also, this study was limited to a private clinic and the fact is that a walk-in clinic might attract a particular group among the population; the generalization of this study should therefore be considered with caution.

\section{Conclusion}

We found that mental disorders comprise a spectrum of disorders, which consist mainly of psychotic, mood, and neurotic disorders. They affect the most productive age groups, affecting the economic status of the person and a country as a whole. They are common in both rural and urban areas and almost equally affect both the genders. The awareness program in public about symptoms of mental disorders will definitely help in early diagnosis and prompt treatment.

Some measures need to be taken to understand the causes of dropout and improve the dropout rates. It could be effective to employ one or two local people who could visit people who have dropped out and try to understand their problems. Future studies should compare the clinical and demographic profiles of patients attending various types of mental healthcare facilities at different levels.

\section{References}

1. Nkomo SDG, Rodriguez J, Keste D, et al. Mental health atlas 2014. Geneva: World Health Organization; 2014.

2. Bryan B, Ryan ND, Williamson DE. Childhood and adolescent depression. A review of past 10 years. J Am Acad Child Adolesc Psychiatary 1996;35(11):1427-1439. DOI: 10.1097/00004583-199611000-00011.

3. Kohn R, Saxena S, Levav I, et al. The treatment gap in mental health care. Bull World Health Organ 2004;82(11):858-866. DOI: /S004296862004001100011.

4. Jacob KS, Sharan P, Mirza I, et al. Mental health systems in countries: where are we now? Lancet 2007;370(9592):1061-1077. DOI: 10.1016/ S0140-6736(07)61241-0.
5. World Health Organization. Depression Factsheet $\mathrm{N}^{*} 369$ [online] Oct2014 [cited June 2015] Available from URL: [http//www.who.int/ media centre/ factsheet/fs369/en/].

6. World Health Organization/ Europe [online] European Health Report 2014. [cited may 2015] Available at URL: [http//www.euro.who.int/en/ health-topics/.../mental-health/data-and-statistic].

7. Herman AA, Stein DJ, Seedat $S$, et al. The South African stress and health (SASH) study: 12-month and lifetime prevalence of common mental disorders. S Afri Med J 2009;9(5):339-344.

8. World Health Organization 2015. International public health hazards: Indian legislative provisions. Available at URL: [http//www.who.org. indian/ legis/pub.healthhaz/en].

9. World Health Organization. The ICD-10 Classification of Mental and Behavioral disorders (Tenth Revision): Diagnostic Criteria for Research. Geneva; 1992.

10. Khattri JB, Godar ST, Thapa P, et al. Socio-demographic characteristics and diagnostic profile of patients attending psychiatric OPD of a private hospital in western region of Nepal. Nepal J Med Sci 2012;1(1):15-18. DOI: 10.3126/njms.v1i1.5790.

11. Kameshvell, Rajin S, Raj Kumar P. Morbidity pattern among patients attending a private psychiatric clinic - A cross sectional study. Sch J App Med Sci 2016;4(9D):3462-3466. DOI: 10.21276/sjams.2016.4.9.60.

12. Jaju S, Al-Adawi S, Al-Kharusi H, et al. Prevalence and age of-onset distributions of DSMIV mental disorders and their severity among school going Omani adolescents and youths: WMH-CIDI findings. Child Adol Psych Ment Health 2009;3(1):29. DOI: 10.1186/1753-2000-3-29.

13. Soren $S$, Bhutto ZA, Kumari $P$, et al. A socio-demographic study of patients attending DMHP, Dumka. Eastern J Psychiatry 2008;11:9-13.

14. Al-Adawi S, Jaju SS, Al-Zakwani I, et al. Culture to culture fatphobia and somatization. In: Preedy VR, Watson RR, Martin CR, ed. International Handbook of Behavior, Diet, and Nutrition. New York: Springer; 2011. pp. 1457-1473.

15. Ghaleiha A, Afzali S, Bazyar M, et al. Characteristics of hospitalized patients following suicide attempt in Hamadan district, Iran. Oman Med J 2012;27(4):304-309. DOI: 10.5001/omj.2012.75.

16. Rosenfield S. Gender and mental health: do women have more psychopathology, men more, or both the same (and why)? In: Horwitz AV, Scheid TL, ed. A Handbook for the Study of Mental Health: Social Contexts, Theories, and Systems. New York, NY, US: Cambridge University Press; 1999. pp. 348-360.

17. Bagadia VN, Ayyar KS, Lakdawala PD, et al. Psychiatric morbidity among patients attending medical outpatient department. Ind J Psychiat 1986;28(2):139.

18. Regmi SK, Khalid A, Nepal MK, et al. A study of socio-demographic characteristics and diagnostic profile in psychiatric outpatients of TUTH. Nepalese Journal of Psychiatry 1999;1(1):26-33.

19. Shrestha NM, A prospective analysis of 300 cases attending outpatient clinic in Mental Hospital. In: Proceedings of the Workshop on National Mental Health Planning, Kathmandu; 1987. pp. 47-73.

20. Baker KA, Dwairy M. Cultural norms versus state law in treating incest: a suggested model for Arab families. Child Abuse Negl 2003;27(1):109-123. DOI: 10.1016/S0145-2134(02)00505-7.

21. Fahmida A, Wahab MA, Rahman MM. Pattern of psychiatric morbidity among the patients admitted in a private psychiatric clinic. Bangladesh J Medl Sci 2009;8(1-2):23-28.

22. Shakya DR. Psychiatric morbidities among mentally ill wives of Nepalese men working aboard. Ind Psychiatry J 2014;23(1):52-57. DOI: 10.4103/0972-6748.144957.

23. Shakya DR, Mental Health in New Nepal. In: Souvenir of the 24 All Nepal medical Conferences (ANEMECON);2009;62-64.

24. Choo CH. Profile of patients seeking psychiatric treatment from the adult public mental health services in Singapore. Ann Acad Med Singapore 1997;26(4):443-448.

25. Uys LR, Dlamini NK, Mabandla SP. A profile of selected psychiatric out patients in South Africa. Curationis 1995;18(1):22-25. DOI: 10.4102/ curationis.v18i1.1348.

26. Dubey KC. A study of prevalence and biosocial variables in mental illness in a rural and urban community in Uttar Pradesh, India. Acta 
Psychiatr Scand 1970;46(4):327-359. DOI: 10.1111/j.1600-0447.1970. tb02124.x.

27. Wig NS, Murthy RS, Harding TW. A model for rural psychiatric services - Raipur rani experience. Indian J Psychiatry 1981;23(4):275-290.

28. Wright C, Community mental health services in Nepal-early experiences. In: Proceedings of the Workshop on National Mental Health Planning, Kathmandu; 1987. pp. 13-27.

29. Sharma BB, Socio-demographic analysis of 100 cases seen at Pokhara Mental Health Clinic. In: Proceedings of the Workshop on National Mental Health Planning, Kathmandu; 1987;74-82.

30. Agarwal AK. Analysis of patients attending a private psychiatric clinic. Indian J Psychiatry 2012;54(4):356-358. DOI: 10.4103/00195545.104824 .
31. Reddy VM, Chandrashekar CR. Prevalence of mental and behavioral disorders in India: a metaanalysis. Indian J Psychiatry 1998;40(2):149-157.

32. Venkatesh BK, Thirtalli J, Naveen MN, et al. Sex difference in age of onset of schizophrenia: finding from community based study in India. World psychiatry 2008;7(3):173-176. DOI: 10.1002/j.2051-5545.2008. tb00191.x.

33. Mclean CP, Asnani A, Litz BT, et al. Gender difference in anxiety disorders: prevalence, course of illness, co-morbidity and burden of illness. J psychiatry Res 2011;45(8):1027-1035. DOI: 10.1016/j. jpsychires.2011.03.006.

34. Rahman F, Sabeka MM, Karim ME. Psychiatric co-morbidity and sexual dysfunction in substance use disorder. Bang J Psychiatry 2003;17(2):1421. 